\title{
Clinical and Radiological Outcomes of Microscopic Lumbar Foraminal Decompression: A Pilot Analysis of Possible Risk Factors for Restenosis
}

\author{
Shoichi HAIMOTO, ${ }^{1}$ Yusuke NishIMURA, ${ }^{1}$ Masahito HARA,${ }^{2}$ Yasuhiro NAKAJIMA, ${ }^{2}$ \\ Yu YAMAMOTO, ${ }^{2}$ Howard J. GINSBERG ${ }^{3}$ and Toshihiko WAKABAYASHI ${ }^{1}$ \\ ${ }^{1}$ Department of Neurosurgery, Nagoya University Graduate School of Medicine, \\ Nagoya, Aichi, Japan; \\ ${ }^{2}$ Department of Neurosurgery, Inazawa Municipal Hospital, Inazawa, Aichi, Japan; \\ ${ }^{3}$ Division of Neurosurgery, St. Michael's Hospital, University of Toronto, Toronto, Canada
}

\begin{abstract}
A single-center retrospective comparative study was designed to identify the risk factors for restenosis of lumbar foraminal stenosis (LFS) after microscopic foraminal decompression (MFD). 21 consecutive patients who underwent single-level MFD with an average of 19-month follow-up were divided into two study groups based on clinical outcomes; group 1 ( 7 patients with poor outcomes requiring revision surgery), group 2 (14 patients with good outcomes with no revision surgery required). Changes of lumbar spinal alignment on plain standing radiographs were compared and analyzed between two study groups to investigate the pathology and risk factors associated with restenosis after MFD. Preoperative disc wedging (DW) angle was significantly larger in group 1 than in group $2\left(3.5 \pm 1.0^{\circ}\right.$ vs $\left.1.1 \pm 0.2^{\circ}, P<0.01\right)$. Postoperatively, disc height $(\mathrm{DH})$ and foraminal height $(\mathrm{FH})$ decreased $(P<0.05)$, and DW deteriorated $(P<$ 0.01) significantly in group 1 , while there were no significant changes in group 2. Lumbar lordosis (LL) remarkably improved postoperatively in group $2(24.7 \pm 8.0$ to $32.0 \pm 7.0, P<0.001)$, contrary to limited improvement in group $1(25.1 \pm 9.2$ to $27.0 \pm 12.0, P=0.45)$. Postoperative $L L$ is a predictive factor for restenosis after MFD. Decrease in DH or progression of DW was contributing to restenosis. LFS presenting with large DW and lumbar degenerative kyphosis should be excluded from surgical indications for MFD without instrumented fusion, considering the high recurrence rate.
\end{abstract}

Key words: lumbar foraminal stenosis, microscopic foraminal decompression, sagittal alignment, lumbar lordosis, disc wedging

\section{Introduction}

Lumbar foraminal stenosis (LFS) is a common cause of lumbar nerve root entrapment, which has been reported to occur in $8-11 \%$ of lumbar degenerative diseases. ${ }^{1-3)}$ Although this pathological condition is less common than lumbar canal stenosis (LCS), surgical treatment for LFS is increasingly important, as the clinical entity has become widely recognized. Two types of surgical options are suggested, such as microscopic foraminal decompression (MFD) or posterior lumbar-instrumented

Received May 24, 2017; Accepted September 13, 2017

Copyright@ 2018 by The Japan Neurosurgical Society This work is licensed under a Creative Commons AttributionNonCommercial-NoDerivatives International License. fusion. While several studies have described that $5-14 \%$ of LFS cases after MFD required revision surgery due to recurrent symptoms, ${ }^{4-6)}$ the efficacy, minimal invasiveness and cost effectiveness of MFD have been verified, ${ }^{4-7}$ given the potential risks of instrumented fusion, such as surgical site infection, screw misplacement, screw loosening and adjacent segment diseases. We need to have a further discussion on risk factors for recurrence to improve the outcomes of MFD. Lumbar spinal alignment is thought to be profoundly related to the surgical outcomes of MFD. Yamada et al. reported that coronal malalignment, such as scoliosis progression, is one of the causes of recurrence after MFD. $\left.{ }^{4}\right)$ However, no study has elucidated radiological changes of lumbar sagittal alignment after MFD even as sagittal malalignment has drawn 
much attention as an important pathogenesis of lumbar degeneration.

The purpose of this pilot study was to scrutinize the potential risk factors for restenosis after MFD by retrospective evaluation of the clinical and radiological outcomes of MFD with an emphasis on lumbar sagittal alignment.

\section{Materials and Methods}

\section{Patients}

This clinical analysis was designed as a singlecenter retrospective comparative study. Following Research Ethics Board's approval at Nagoya University Hospital, clinical and radiological outcomes of 21 consecutive patients with an average age of 64.7-yearold (range 34-74) having undergone MFD for LFS from 2007 to 2014 were retrospectively reviewed. All surgeries were performed by the senior author. The diagnosis of LFS was based on the presence of clinical symptoms of lumbar radiculopathy, combined with corresponding radiographical findings, such as disappearance of perineural fat tissue in the intervertebral foramen as well as "root lift-up sign" proposed by Chang et al. on magnetic resonance imaging (MRI). ${ }^{6)}$ Exclusion criteria included those patients with isthmic spondylolisthesis and lumbar instability which satisfied one or more of the following criteria on flexion and extension standing radiographs: (1) segmental kyphosis $\geqq 5^{\circ}$ in flexion, (2) segmental range of motion (ROM) $\geqq$ $15^{\circ}$ in flexion-extension, (3) deterioration of sagittal translation $\geqq 3 \mathrm{~mm}$ in flexion-extension. Surgical treatment was indicated only when symptoms were resistant to conservative therapy for more than 3 months. 8 male and 13 female patients were eventually qualified for this study with a minimum of 6-month follow-up (average 19 months, range 6-54 months). All patients underwent single-level MFD with 1 patient (5\%) at L3/4, 2 patients $(10 \%)$ at L4/5 and 18 patients (85\%) at L5/S. Four patients had undergone previous lumbar laminectomy for LCS.

\section{Assessment of clinical outcomes}

Clinical outcomes were evaluated using the Japanese Orthopedic Association (JOA) scores preoperatively, 1 week postoperatively, 6 months postoperatively, and at final follow-up. Macnab scales $^{8)}$ were also assessed 1 week postoperatively, 6 months postoperatively and at final follow-up. If a revision surgery was performed at the index segment because of recurrent leg pain and lower back pain, these scores at final follow-up were obtained just before the revision surgery. Patients were divided into two groups based on their clinical outcomes for the comparative study; group 1 consisted of patients who required revision surgery because of recurrent symptoms and group 2 consisted of successfullytreated patients with no revision surgery required.

\section{Assessment of radiological changes}

Plain standing dynamic and static radiographs were obtained for all patients preoperatively, 6 months postoperatively, and at final follow-up (Fig. 1). They were assessed for following radiological parameters; (1) LL (lumbar lordosis; sagittal Cobb angle measured between the lower endplate of Th12 vertebra and the upper endplate of S1 vertebra), (2) CA (coronal Cobb angle), (3) LROM (range of motion of LL in flexion-extension), (4) DH (disc height; an average of the anterior and posterior disc heights), (5) FH (foraminal height; distance between the pedicles), (6) DW (disc wedging; coronal angle between the line parallel to the lower endplate of superior vertebra and the line parallel to the upper endplate of inferior vertebra), (7) SLA (segmental lordotic angle; sagittal Cobb angle of the index level) and (8) SROM (ROM of SLA in flexion-extension). When the index level was L5/S, DW was calculated as the angle between the line parallel to the upper endplate of L5 vertebra and the line connecting the tops of bilateral sacral ala in accordance with the previous report. ${ }^{9)}$

\section{Pathogenesis of LFS}

Preoperative MRI and computed tomography (CT) were used to assess and categorize the pathogenesis of LFS into 3 types as proposed by Kunogi et al. ${ }^{1)}$ (Fig. 2). (1) anteroposterior LFS: the superior articular process of inferior vertebra is kissing to the superior pedicle, (2) cephalocaudal LFS: posterolateral osteophyte of the vertebral body or laterally bulging herniated disc is protruding into the neural foramen in distance of more than $3 \mathrm{~mm}$, (3) circumferential LFS: both findings of anteroposterior and cephalocaudal stenosis.

\section{Surgical procedure}

We adopted either of two surgical procedures for each case: medial foraminotomy or lateral foraminotomy. All procedures were conducted under microscopic magnification.

Medial foraminotomy was selected for LFS with coexisting canal stenosis at the corresponding level or LFS limited to the medial aspect of the foramen. A skin incision was made in the midline with a patient placed in the prone position. Firstly, lumbar laminectomy via a spinous process-splitting method was performed as previously described ${ }^{10)}$ for decompression of the coexisting canal stenosis. Then, the foramen was unroofed by resecting the medial 

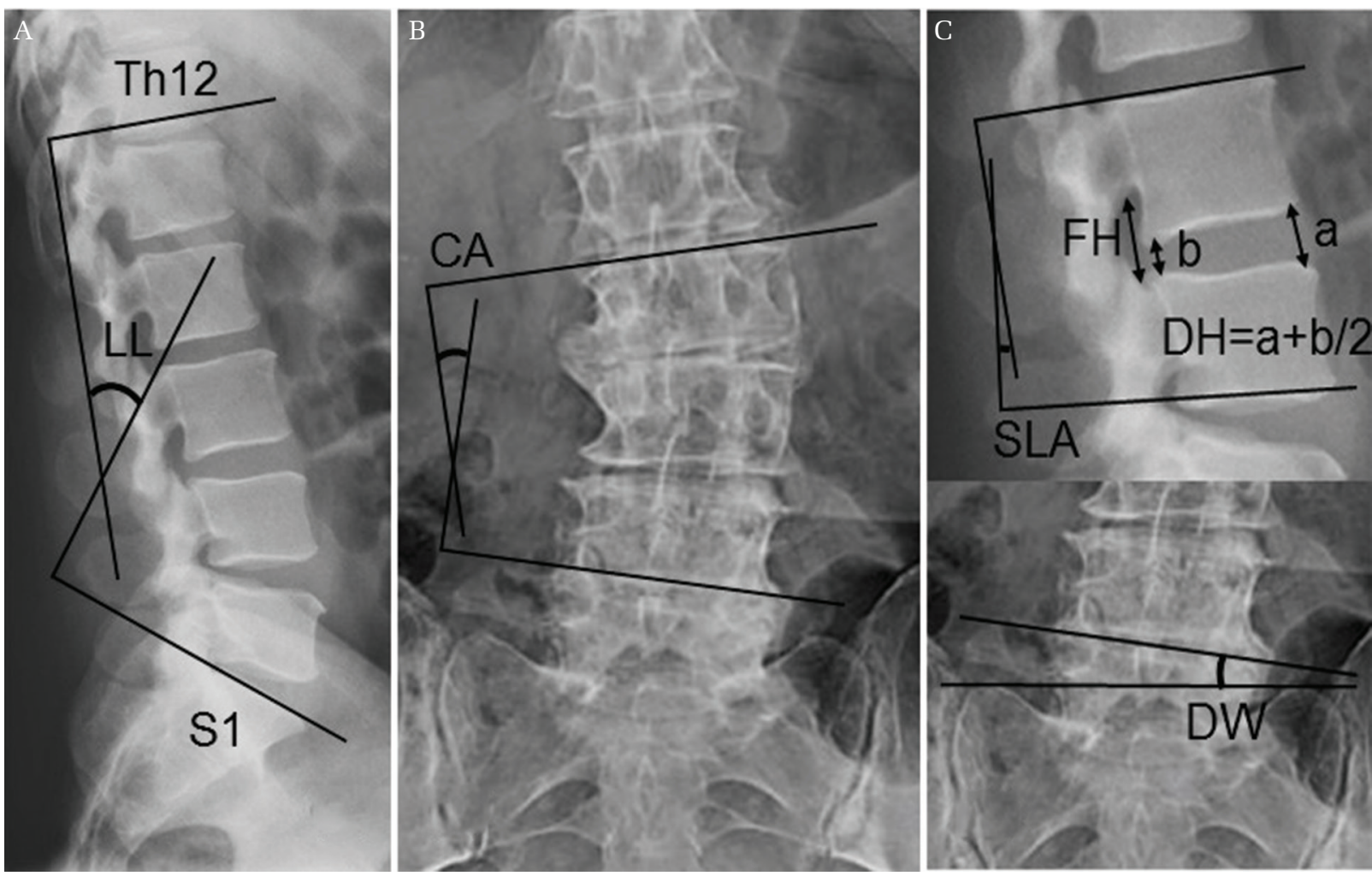

Fig. 1 Diagram showing the measurement of lumbar lordosis (LL) (A), coronal Cobb angle (CA) (B), as well as disc height (DH), foraminal height (FH), segmental lordotic angle (SLA), and disc wedging (DW) (C). DH was measured as an average of anterior and posterior disc heights. When the index level was L5/S, DW was calculated as the angle between the line tangential to the upper endplate of L5 vertebra and the line connecting the tops of bilateral sacral ala.

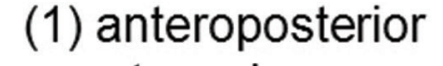
stenosis

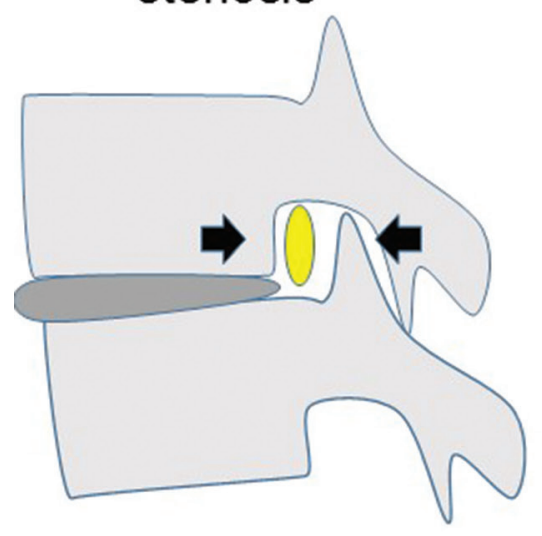

(2) cephalocaudal stenosis

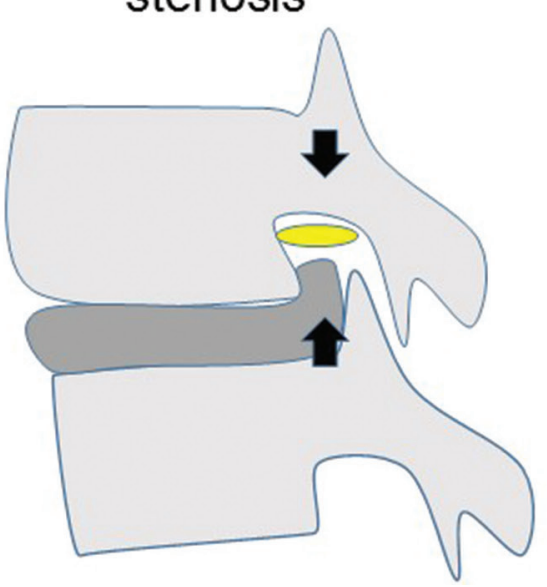

(3) circumferential stenosis

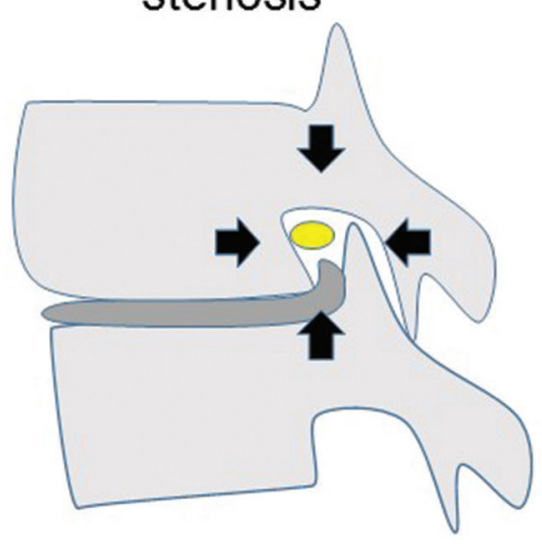

Fig. 2 Scheme showing the classification of the pathogenesis of lumbar foraminal stenosis. Yellow circles show the nerve root. Black arrows show the direction of nerve root compression.

part of pars interarticularis and the upper part of superior articular process of the inferior vertebra using high-speed drill and Kerrison rongeur. More than $5 \mathrm{~mm}$ of the dorsal cancellous bone of the pars interarticularis was preserved not to induce iatrogenic spondylolysis. In case of cephalocaudal or circumferential LFS, protruded posterolateral osteophyte or bulging herniated disc was removed. 
Mobility of the nerve root was confirmed at the final stage.

Lateral foraminotomy was our procedure of choice for LFS without coexisting canal stenosis. A skin incision was made approximately $4 \mathrm{~cm}$ off midline with a patient placed in the prone position. The lateral exit zone of the foramen was approached through the fascial plane between multifidus and longissimus muscles (Wiltse paraspinal approach). Unroofing of the foramen was performed by resecting the upper part of superior articular process of the inferior vertebra and the lateral part of pars interarticularis using high-speed drill and Kerrison rongeur. Only a quarter of the lateral part of pars interarticularis was removed not to induce iatrogenic spondylolysis. ${ }^{11)}$ In case of cephalocaudal or circumferential LFS, protruded posterolateral osteophyte or bulging herniated disc was removed. Mobility of the nerve root was confirmed at the final stage.

\section{Statistical analysis}

Statistical differences in clinical and radiological data were analyzed between group 1 and 2. Results are represented as mean \pm standard deviation. Categorical variables were compared using $\chi^{2}$ tests, and continuous variables were compared using student $t$-tests. A $P$ value of less than 0.05 was considered statistically significant. All statistical analyses were performed using SPSS 22.0 statistics package (IBM Corporation, Armonk, NY).

\section{Results}

\section{Clinical outcomes}

4 patients (3 with coexisting canal stenosis, 1 with LFS limited to the medial aspect of the foramen) underwent medial foraminotomy, and the remaining 17 patients underwent lateral foraminotomy. There were no complications associated with the initial surgery (MFD). All patients improved neurologically at 1 week postoperatively. However, 7 patients showed recurrent symptoms with an average recurrence interval of 15.8 months (range 3-40 months). Macnab scales are summarized in Table 1. Eventually, patients with either excellent or good outcomes declined to $67 \%$ (14 patients) of all patients at final follow-up, who were assigned to group 2 (14 patients). All 7 patients (33\%) with either fair or poor outcomes deriving from recurrent symptoms underwent revision surgery at final follow-up, who were assigned to group 1 ( 7 patients). Transforaminal lumbar interbody fusion (TLIF) was performed as revision surgery for all patients in group 1, all of whom made good recovery after TLIF. The preoperative JOA scores of both
Table 1 Surgical outcome in Macnab scale

\begin{tabular}{lccc}
\hline & $\begin{array}{c}\text { 1-week } \\
(\%)\end{array}$ & $\begin{array}{c}\text { 6-month } \\
\text { follow-up (\%) }\end{array}$ & $\begin{array}{c}\text { Final } \\
\text { follow-up (\%) }\end{array}$ \\
\hline Excellent & $14(67)$ & $8(38)$ & $8(38)$ \\
Good & $7(33)$ & $10(47)$ & $6(29)$ \\
Fair & 0 & $2(10)$ & $5(23)$ \\
Poor & 0 & $1(5)$ & $2(10)$ \\
\hline
\end{tabular}

groups were similar $(15.4 \pm 2.1$ and $15.1 \pm 5.1$ for group 1 and 2, respectively). Scores significantly improved in both groups 1 week $(21.1 \pm 3.4$ and $24.3 \pm 2.5$ for group 1 and 2, respectively) and 6 months postoperatively $(19.2 \pm 3.8$ and $24.2 \pm 2.5$ for group 1 and 2, respectively). At final follow-up, JOA scores significantly deteriorated in group 1 $(15.2 \pm 2.9)$ while they were maintained in group $2(24.4 \pm 2.7)$ (Table 2).

\section{Patient demographics}

Comparison of preoperative clinical and radiological data between the two groups are summarized in Table 2. There were no significant differences in all items except for JOA scores. The followup period was 22.2 months (range 6-32 months) in group 1 and 17.7 months (range 6-54 months) in group 2 on average.

\section{Preoperative radiological parameters}

Statistical analysis of preoperative radiological parameters revealed that DW was significantly larger in group $1\left(3.5 \pm 1.0^{\circ}\right)$ than in group 2 (1.1 $\pm 0.2^{\circ}$ ). Other radiological parameters did not show any statistically significant differences (Table 3).

\section{Comparison between pre- and post-operative radiological parameters}

Postoperative radiological parameters at 6-month postoperative follow-up and at final follow-up were analyzed and compared with the preoperative values (Table 4). In group $1, \mathrm{DH}$ and $\mathrm{FH}$ showed significant decrease from the preoperative values at final follow-up. Progression of DW at final follow-up was also statistically significant, which became one of the contributing factors of recurrent neurological symptoms as shown in Fig. 3. These changes were not statistically significant at 6-month postoperative follow-up. In group 2, LL showed remarkable improvement postoperatively from $24.7^{\circ} \pm 8.0^{\circ}$ to $32.2^{\circ} \pm 7.0^{\circ}$ and $32.0^{\circ} \pm 7.0^{\circ}$ at 6 -month postoperative and final follow-up respectively, in contrast to limited improvement in group 1 from $25.1^{\circ} \pm$ $9.2^{\circ}$ to $27.4^{\circ} \pm 11.0^{\circ}$ and $27.0^{\circ} \pm 12.0^{\circ}$ at 6 -month postoperative and final follow-up respectively. Other 
Table 2 Comparison of clinical data between the study groups

\begin{tabular}{|c|c|c|c|}
\hline & $\begin{array}{c}\text { Revision surgery }(+) \\
\text { Group } 1 \\
n=7\end{array}$ & $\begin{array}{c}\text { Revision surgery }(-) \\
\text { Group } 2 \\
n=14\end{array}$ & $P$ \\
\hline \multicolumn{4}{|l|}{ Sex } \\
\hline Male & 2 & 6 & \multirow[t]{2}{*}{0.52} \\
\hline Female & 5 & 8 & \\
\hline BMI (kg/cm²), mean (range) & $23.6(21.8-26.9)$ & $23.7(18.7-27.3)$ & 0.93 \\
\hline \multicolumn{4}{|l|}{ Affected level } \\
\hline $\mathrm{L} 3 / 4$ & 0 & 1 & \multirow{2}{*}{0.09} \\
\hline $\mathrm{L} 4 / 5$ & 2 & 0 & \\
\hline Right & 4 & 8 & 1.00 \\
\hline \multicolumn{4}{|l|}{ Surgical procedure } \\
\hline Medial foraminotomy & 2 & 2 & \multirow[t]{2}{*}{0.43} \\
\hline Lateral foraminotomy & 5 & 12 & \\
\hline Follow-up period (months), mean (range) & $22.2(6-32)$ & $17.7(6-54)$ & 0.52 \\
\hline \multicolumn{4}{|l|}{ Pathogenesis } \\
\hline Anteroposterior stenosis & 0 & 1 & \multirow{2}{*}{0.16} \\
\hline Cephalocaudal stenosis & 1 & 7 & \\
\hline Final follow-up & $15.2 \pm 2.9$ & $24.4 \pm 2.7$ & $<0.001$ \\
\hline
\end{tabular}

BMI: body mass index.

Table 3 Comparison of preoperative radiological data between the study groups

\begin{tabular}{|c|c|c|c|}
\hline & $\begin{array}{c}\text { Revision surgery }(+) \\
\text { Group } 1 \\
n=7\end{array}$ & $\begin{array}{c}\text { Revision surgery }(-) \\
\text { Group } 2 \\
n=14\end{array}$ & $P$ \\
\hline Coronal Cobb angle $\left(^{\circ}\right)$ & $5.0 \pm 1.2$ & $4.8 \pm 0.8$ & 0.91 \\
\hline Lumbar lordosis $\left({ }^{\circ}\right)$ & $25.1 \pm 9.2$ & $24.7 \pm 8.0$ & 0.91 \\
\hline Lumbar ROM in flexion-extension $\left(^{\circ}\right)$ & $29.6 \pm 8.3$ & $34.0 \pm 13.0$ & 0.42 \\
\hline Disc height (mm) & $6.9 \pm 1.9$ & $7.6 \pm 1.9$ & 0.45 \\
\hline Foraminal height (mm) & $17.2 \pm 2.6$ & $16.5 \pm 3.1$ & 0.6 \\
\hline Disc wedging $\left(^{\circ}\right)$ & $3.5 \pm 1.0$ & $1.1 \pm 0.2$ & 0.005 \\
\hline Segmental lordotic angle $\left(^{\circ}\right)$ & $6.9 \pm 4.0$ & $8.3 \pm 3.0$ & 0.4 \\
\hline Segmental ROM in flexion-extension $\left(^{\circ}\right)$ & $4.7 \pm 1.6$ & $5.3 \pm 2.3$ & 0.55 \\
\hline
\end{tabular}


Table 4 Postoperative radiological changes in both groups

\begin{tabular}{|c|c|c|c|c|c|}
\hline & \multirow{2}{*}{$\begin{array}{l}\text { Preoperative } \\
\text { Mean } \pm \text { SD }\end{array}$} & \multicolumn{2}{|c|}{ 6-month follow-up } & \multicolumn{2}{|c|}{ Final follow-up } \\
\hline & & Mean \pm SD & $P^{*}$ & Mean \pm SD & $P^{*}$ \\
\hline \multicolumn{6}{|l|}{ Group 1} \\
\hline Coronal Cobb angle ( $\left.{ }^{\circ}\right)$ & $5.0 \pm 1.2$ & $5.0 \pm 0.9$ & 0.97 & $5.2 \pm 1.2$ & 0.67 \\
\hline Lumbar lordosis $\left(^{\circ}\right)$ & $25.1 \pm 9.2$ & $27.4 \pm 11.0$ & 0.09 & $27.0 \pm 12.0$ & 0.45 \\
\hline $\begin{array}{l}\text { Lumbar ROM in flexion- } \\
\text { extension }\left(^{\circ}\right)\end{array}$ & $29.6 \pm 8.3$ & $32.2 \pm 6.8$ & 0.30 & $26.5 \pm 13.8$ & 0.49 \\
\hline Disc height (mm) & $6.9 \pm 1.9$ & $6.7 \pm 1.9$ & 0.06 & $5.5 \pm 1.9$ & 0.04 \\
\hline Foraminal height (mm) & $17.2 \pm 2.6$ & $16.6 \pm 3.3$ & 0.10 & $15.8 \pm 3.4$ & 0.01 \\
\hline Disc wedging $\left({ }^{\circ}\right)$ & $3.5 \pm 1.0$ & $3.6 \pm 2.6$ & 0.37 & $4.6 \pm 1.0$ & 0.003 \\
\hline Segmental lordotic angle $\left(^{\circ}\right)$ & $6.9 \pm 4.0$ & $6.8 \pm 4.2$ & 0.76 & $6.9 \pm 4.8$ & 0.94 \\
\hline $\begin{array}{l}\text { Segmental ROM in flexion- } \\
\text { extension }\left(^{\circ}\right)\end{array}$ & $4.7 \pm 1.6$ & $4.6 \pm 1.3$ & 0.86 & $4.3 \pm 2.2$ & 0.67 \\
\hline \multicolumn{6}{|l|}{ Group 2} \\
\hline Coronal Cobb angle $\left({ }^{\circ}\right)$ & $4.8 \pm 0.8$ & $3.9 \pm 0.7$ & 0.06 & $4.0 \pm 0.7$ & 0.09 \\
\hline Lumbar lordosis $\left(^{\circ}\right)$ & $24.7 \pm 8.0$ & $32.2 \pm 7.0$ & $<0.001$ & $32.0 \pm 7.0$ & $<0.001$ \\
\hline $\begin{array}{l}\text { Lumbar ROM in flexion- } \\
\text { extension }\left(^{\circ}\right)\end{array}$ & $34.0 \pm 13.0$ & $33.5 \pm 14.5$ & 0.72 & $33.3 \pm 14.2$ & 0.48 \\
\hline Disc height (mm) & $7.6 \pm 1.9$ & $7.4 \pm 1.9$ & 0.23 & $7.3 \pm 1.9$ & 0.17 \\
\hline Foraminal height (mm) & $16.5 \pm 3.1$ & $16.1 \pm 2.9$ & 0.42 & $16.1 \pm 3.0$ & 0.34 \\
\hline Disc wedging $\left(^{\circ}\right)$ & $1.1 \pm 0.1$ & $0.9 \pm 0.5$ & 0.36 & $1.1 \pm 0.2$ & 0.91 \\
\hline Segmental lordotic angle $\left(^{\circ}\right)$ & $8.3 \pm 3.0$ & $8.6 \pm 3.0$ & 0.63 & $9.4 \pm 4.1$ & 0.17 \\
\hline $\begin{array}{l}\text { Segmental ROM in flexion- } \\
\text { extension }\left(^{\circ}\right)\end{array}$ & $5.3 \pm 2.3$ & $4.3 \pm 2.1$ & 0.08 & $4.8 \pm 3.0$ & 0.51 \\
\hline
\end{tabular}

${ }^{*}$ Compared with preoperative data.

parameters including $\mathrm{DH}, \mathrm{FH}$ and DW did not show any deterioration in group 2 as shown in Fig. 4.

\section{Discussion}

Spinal instrumented fusion is one of the surgical options for LFS, which can accomplish restoration of disc height, adequate foraminal decompression brought on by total facetectomy and eliminate dynamic factors contributing to the pathogenesis of LFS. However, as LFS mostly occurs in elderly patients due to its degenerative nature, ${ }^{2)}$ we should take into account the invasiveness, longer operative time, larger amount of blood loss and cost effectiveness as well as surgical risks associated with spinal instrumentation, such as surgical site infection, screw misplacement, screw loosening, and adjacent segment diseases. ${ }^{12)}$ Therefore, less invasive procedures such as MFD may be favorable by avoiding the potential risks associated with spinal instrumented fusion. Previous studies have demonstrated the efficacy of MFD for LFS. Kim et al. concluded both of decompressionalone procedure and posterior instrumented fusion have equivalent clinical outcomes. ${ }^{5)}$ Yamada et al. reported satisfactory outcomes of MFD using partial pediculectomy. ${ }^{4)}$ Chang et al. also reported excellent surgical results of MFD via a posterolateral transmuscular approach. ${ }^{6)}$ However, they also described that $5-14 \%$ of LFS cases required revision surgery due to recurrent symptoms after MFD. Recurrence of neurological symptoms has been reported to occur within 11-23-month postoperative period, which is equivalent to our outcomes. ${ }^{4,7)}$ Considering that MFD is still a technically challenging surgical procedure and revision surgery could be required in some cases, further investigation is essential to clarify the characteristics of radiological parameters associated with recurrence after MFD. Recent studies have reported the imaging characteristics of symptomatic LFS. Ohba et al. described that symptomatic LFS has significantly smaller LL and shorter DH, as well as greater scoliosis and DW compared with LCS. ${ }^{13)}$ Murata et al. confirmed that dynamic motion of L5/S disc with vacuum phenomena triggered symptoms of LFS. ${ }^{14)}$

The present study demonstrated that postoperative little improvement of LL would be a predictive factor for restenosis after MFD. LL improved 

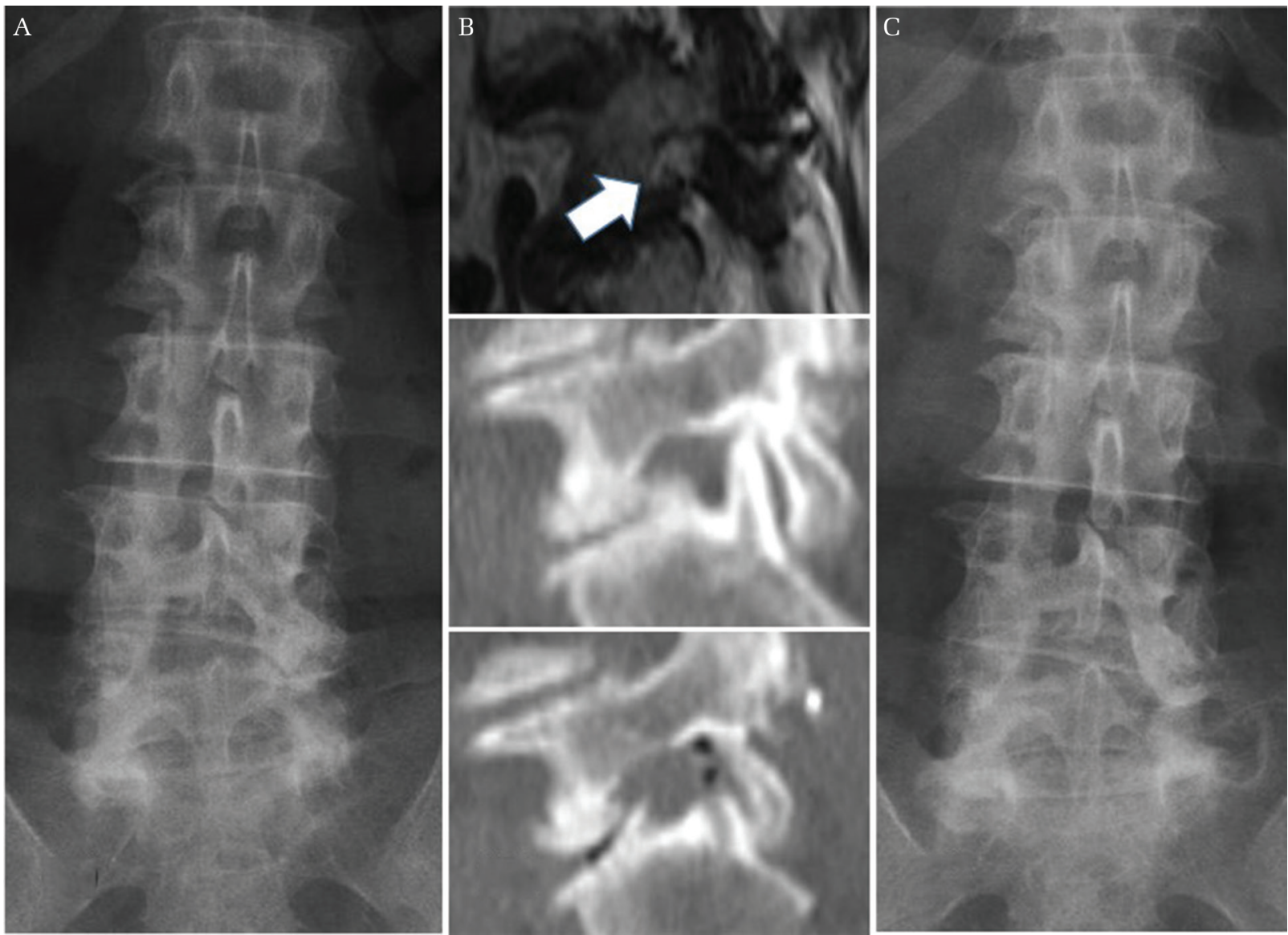

Fig. 3 A representative case of recurrence of LFS due to progression of disc wedging. A 67-year-old woman underwent a lateral foraminotomy for left L5/S foraminal stenosis. Her preoperative radiograph showed $8.2^{\circ}$ of disc wedging at L5/S concave to the left (A). Her MRI and CT demonstrated circumferential stenosis of the left neural foramen at L5/S, and sufficient decompression was achieved after surgery (B) (upper; preoperative MRI sagittal image, middle; preoperative CT sagittal image, lower; postoperative CT sagittal image, white arrow demonstrates narrowed neural foramen). 14 months after the initial surgery, she underwent a revision TLIF because of recurrent radiculopathy. At the time of recurrence, her radiograph showed significant progression of disc wedging at L5/S, measuring $9.6^{\circ}$ concave to the left (C). LFS: lumbar foraminal stenosis, MRI: magnetic resonance imaging, CT: computed tomography, TLIF: transforaminal lateral interbody fusion.

dramatically after MFD in group 2 with statistically significance in contrast to limited changes in group 1. It is most likely that preoperative loss of LL in group 2 was reversible and mainly triggered by intolerable leg pain limiting lumbar extension. Pain-related functional kyphosis could be alleviated by pain relief after surgical intervention. Improvement of LL might have a positive influence on other radiological parameters in group 2. On the other hand, in group 1, preoperative loss of LL indicates mostly irreversible degenerative kyphosis because of severe disc degeneration. It is widely recognized that spinal sagittal imbalance, especially loss of LL, is closely correlated with lumbar disc degeneration. ${ }^{15,16)} \mathrm{A}$ biomechanical study also demonstrated that lumbar disc pressure increases with forward flexion of the lumbar spine, which could trigger progressive disc degeneration. ${ }^{17)}$ In the present study, DH and FH significantly decreased, and DW significantly deteriorated after MFD in group 1, contrary to group 2. These progressive degenerative changes are thought to correlate with postoperative LL and may be the main pathology of restenosis after MFD. DW was also considered to be a preoperative risk factor for restenosis. Matsumoto et al. reported clinical outcomes of L5/S extraforaminal decompression, with 4 out of $28(14 \%)$ patients demanding revision surgery mainly due to newly-onset LFS. They discussed that progression of L5/S DW would be the cause of newly-onset LFS after extraforaminal decompression. ${ }^{9)}$ Moreover, MFD reportedly could induce scoliosis progression, carrying higher risks to evoke lateral instability rather than anteroposterier instability. ${ }^{4)}$ 

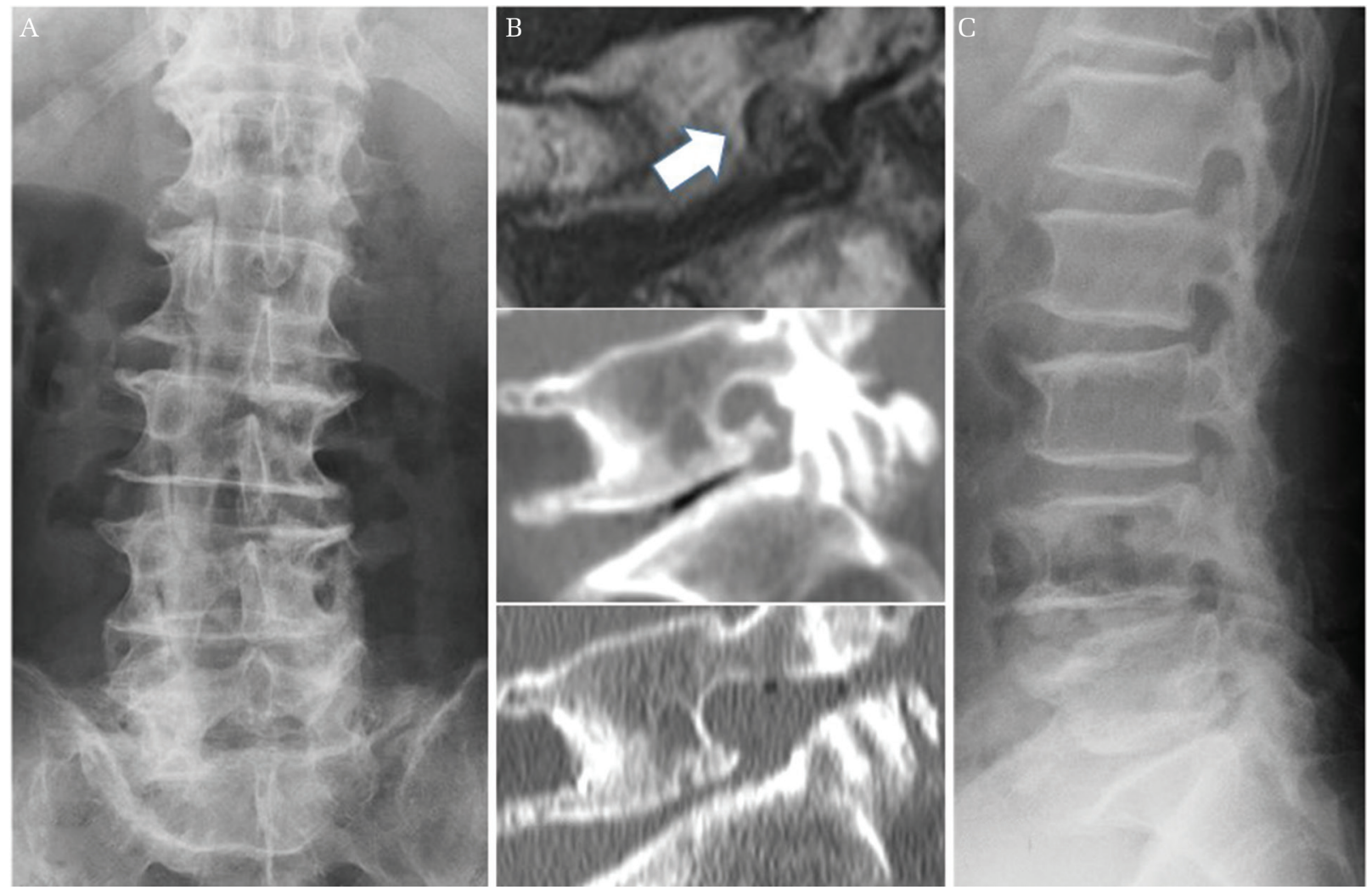

Fig. 4 A representative case with excellent outcome in group 2. A 74-year-old man underwent a lateral foraminotomy for right L5/S LFS. His preoperative radiograph showed $0.4^{\circ}$ of disc wedging at L5/S concave to the right (A), and $35.8^{\circ}$ of lumbar lordosis (not shown). His MRI and CT demonstrated cephalocaudal stenosis of the right neural foramen at L5/S, and sufficient decompression was achieved after surgery (B) (upper; preoperative MRI sagittal image, middle; preoperative CT sagittal image, lower; postoperative CT sagittal image, white arrow demonstrates narrowed neural foramen). 18 months after surgery, he showed good clinical outcome with no significant deterioration of lumbar alignment. His radiograph at final follow-up showed $0.5^{\circ}$ of disc wedging at L5/S concave to the right (not shown), and $37.4^{\circ}$ of lumbar lordosis (C). LFS: lumbar foraminal stenosis, MRI: magnetic resonance imaging, CT: computed tomography.

Resection of lateral spinal components, such as the facet joint, pars interarticularis as well as the intertransverse ligament on the concave side, might exacerbate asymmetric disc degeneration and promote additional lateral instability. Although further study in larger number of patients is needed to confirm the definite radiological threshold, we should exclude patients with large DW and lumbar degenerative kyphosis from surgical candidates of MFD. Furthermore, excessive removal of the facet joint, pars interarticularis and disc material should be avoided while conducting adequate circumferential nerve root decompression in accordance with the type of LFS.

While all patients made significant improvement after MFD in the present study, 7 patients suffered from recurrent symptoms with an average recurrence interval of 15.8 months, which was equivalent to reported studies. However, the revision rate was $33 \%$, relatively higher than previous studies.
The high revision rate might be attributed to the affected level of LFS with 18 out of 21 (85\%) patients presenting with L5/S LFS. LFS is more likely to occur in lower lumbar segments with the L5 nerve root $(75 \%)$ being mostly involved, followed by L4 $(15 \%)$, L3 (5\%), and L2 (4\%). ${ }^{2)}$ Several studies with low revision rates after decompression-alone procedure included many fewer cases with L5/S LFS than the present study. ${ }^{6,18,19)}$ The dorsal root ganglion/foraminal height ratio becomes maximum at the intraforaminal area of $\mathrm{L} 5 / \mathrm{S},{ }^{20)}$ as the mobility of L5 nerve root is limited by a large L5/S facet joint, iliolumbar ligament, and sacral ala in the extraforaminal area. ${ }^{21,22)}$ These anatomical features increase the incidence of symptomatic LFS at L5/S as well as the recurrence rate after MFD. Surgical indication of MFD could be another important factor. However, it is difficult to compare the indications between the present study and previous reports because surgical strategy of LFS and even definition 
of spinal instability vary greatly, depending on each study or institution. Several studies lacked evaluation of the preoperative radiological parameters including DW. ${ }^{6,18,19)}$ Furthermore, most importantly, all patients with recurrent symptoms agreed to proceed to revision surgery in the present study, which might plausibly explain the increased revision rate. Currently, the indication of revision surgery after MFD is also based on surgeon's decision and patients' wishes because of lack of standard protocols.

There were several limitations in this study, which was a retrospective study with small number of patients with short-term outcomes. To establish a radiological threshold of good surgical indication for LFS, a prospective study with larger number of patients is necessary. Radiological evaluations were only focused in the lumber spine. Whole-spine assessment including pelvic parameters can provide further information regarding coronal and sagittal spinal malalignment.

In conclusion, postoperative little improvement of LL is a predictive factor for restenosis after MFD. Progressive disc degeneration, such as decrease in $\mathrm{DH}$ or deterioration of DW, may correlate with LL, causing restenosis of the intervertebral foramen. LFS cases presenting with large DW and lumbar degenerative kyphosis should be excluded from decompression-alone procedure, considering the high recurrence rate.

\section{Conflicts of Interest Disclosure}

All the authors declare they have no competing of interests.

\section{References}

1) Kunogi J, Hasue M: Diagnosis and operative treatment of intraforaminal and extraforaminal nerve root compression. Spine 16: 1312-1320, 1991

2) Jenis LG, An HS: Spine update. Lumbar foraminal stenosis. Spine 25: 389-394, 2000

3) Porter RW, Hibbert C, Evans C: The natural history of root entrapment syndrome. Spine 9: 418-421, 1984

4) Yamada K, Matsuda H, Cho H, Habunaga H, Kono H, Nakamura H: Clinical and radiological outcomes of microscopic partial pediculectomy for degenerative lumbar foraminal stenosis. Spine 38: E723-E731, 2013

5) Kim HJ, Jeong JH, Cho HG, Chang BS, Lee CK, Yeom JS: Comparative observational study of surgical outcomes of lumbar foraminal stenosis using minimally invasive microsurgical extraforaminal decompression alone versus posterior lumbar interbody fusion: a prospective cohort study. Eur Spine J 24: 388-395, 2015

6) Chang HS, Zidan I, Fujisawa N, Matsui T: Microsurgical posterolateral transmuscular approach for lumbar foraminal stenosis. J Spinal Disord Tech 24: 302-307, 2011

7) Yamada K, Matsuda H, Nabeta M, Habunaga H, Suzuki A, Nakamura H: Clinical outcomes of microscopic decompression for degenerative lumbar foraminal stenosis: a comparison between patients with and without degenerative lumbar scoliosis. Eur Spine J 20: 947-953, 2011

8) Macnab I: Negative disc exploration. An analysis of the causes of nerve-root involvement in sixty-eight patients. J Bone Joint Surg Am 53: 891-903, 1971

9) Matsumoto M, Watanabe K, Ishii K, et al.: Posterior decompression surgery for extraforaminal entrapment of the fifth lumbar spinal nerve at the lumbosacral junction. J Neurosurg Spine 12: 72-81, 2010

10) Watanabe K, Hosoya T, Shiraishi T, Matsumoto M, Chiba K, Toyama Y: Lumbar spinous process-splitting laminectomy for lumbar canal stenosis. Technical note. J Neurosurg Spine 3: 405-408, 2005

11) Ivanov AA, Faizan A, Ebraheim NA, Yeasting R, Goel VK: The effect of removing the lateral part of the pars interarticularis on stress distribution at the neural arch in lumbar foraminal microdecompression at L3-L4 and L4-L5: anatomic and finite element investigations. Spine 32: 2462-2466, 2007

12) Cho KJ, Suk SI, Park SR, et al.: Complications in posterior fusion and instrumentation for degenerative lumbar scoliosis. Spine 32: 2232-2237, 2007

13) Ohba T, Ebata S, Fujita K, Sato H, Devin CJ, Haro H: Characterization of symptomatic lumbar foraminal stenosis by conventional imaging. Eur Spine J 24: 2269-2275, 2015

14) Murata $Y$, Kanaya K, Wada H, et al.: L5 radiculopathy due to foraminal stenosis accompanied with vacuum phenomena of the L5/s disc on radiography images in extension position. Spine (Phila Pa 1976) 40: 1831-1835, 2015

15) Nakashima H, Kawakami N, Tsuji T, et al.: Adjacent segment disease after posterior lumbar interbody fusion: based on cases with a minimum of 10 years of follow-up. Spine 40: E831-E841, 2015

16) Menezes-Reis R, Bonugli GP, Dalto VF, da Silva Herrero CF, Defino HL, Nogueira-Barbosa MH: The association between lumbar spine sagittal alignment and L4-L5 disc degeneration among asymptomatic young adults. Spine 41: E1081-E1087, 2016

17) Alf LN: The lumbar spine. An orthopaedic challenge. Spine (Phila Pa 1976) 1: 59-71, 1976

18) Alimi M, Njoku I Jr, Cong GT, et al.: Minimally invasive foraminotomy through tubular retractors via a contralateral approach in patients with unilateral radiculopathy. Neurosurgery 10 Suppl 3: 436-447; discussion 446-447, 2014 
19) Ahn Y, Oh HK, Kim H, Lee SH, Lee HN: Percutaneous endoscopic lumbar foraminotomy: an advanced surgical technique and clinical outcomes. Neurosurgery 75: 124-133; discussion 132-133, 2014

20) Hasegawa T, Mikawa Y, Watanabe R, An HS: Morphometric analysis of the lumbosacral nerve roots and dorsal root ganglia by magnetic resonance imaging. Spine (Phila Pa 1976) 21: 1005-1009, 1996

21) Hasue M, Kunogi J, Konno S, Kikuchi S: Classification by position of dorsal root ganglia in the lumbosacral region. Spine 14: 1261-1264, 1989
22) Hasegawa T, An HS, Haughton VM: Imaging anatomy of the lateral lumbar spinal canal. Semin Ultrasound CT MR 14: 404-413, 1993

Address reprint requests to: Yusuke Nishimura, $\mathrm{MD}, \mathrm{PhD}$, Department of Neurosurgery, Nagoya University Graduate School of Medicine, 65 Tsurumai-cho, Showa-ku, Nagoya, Aichi 466-8550, Japan. e-mail: yusuken0411@med.nagoya-u.ac.jp 